\title{
Focusing on the Problem, Not the Tool: Acknowledging Technology's Limits
}

\author{
Brent A Williams* \\ Department of Epidemiology and Health Services Research, Geisinger Health System, USA
}

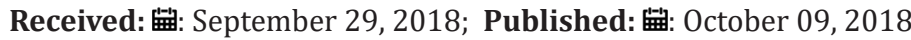

*Corresponding author: Brent A Williams, Geisinger Health System, Department of Epidemiology and Health Services Research,100 North Academy Avenue, USA

\section{Commentary}

One needs to interact only briefly with the outside world to appreciate the ubiquity of technology in contemporary society. The President of the United States tweets, parents ignore their children on the playground while bowing to their smartphones, and airport patrons scurry to camp out at power sources so as to keep their technology fresh for their upcoming travels. Compared to other industries, health care has been accused of slow adoption of innovative technology, but that situation is seemingly changing fast $[1,2]$ From electronic medical records (EMR) to imaging to "-omics", technological advances are having an increasingly noticeable impact in the world of health care, and health care researchers are capitalizing on these advances to fund research programs. Though resistance to such advances by the medical establishment (though not medical researchers) has been noted, few would question the favorable direct or indirect impact some technologies are having in improving human health.

However, in discriminant application of technology becomes counterproductive when it diverts attention from alternative, less technological solutions that may be more practical or cost-efficient. A techno-optimist tends to believe that for most problems there must exist a technological solution which trumps all non-technical ones. A techno-pessimist may ask: Is the problem best solved by a technological solution or is the mere presence of technology a distraction to solving the real issue at hand? For instance, providing widespread clinical decision support through EMRs is wasteful when the majority of clinicians perceive no need or have no desire for such support; counting steps with an electronic wearable device to encourage physical activity seems unlikely to have lasting benefit in the absence of a conducive environment or sufficient internal motivation for long-term maintenance of an exercise regimen; understanding the downstream consequences of obesity in great molecular detail ignores the fact that these unbeknownst molecular aberrations would likely improve with the simplest (though challenging to maintain) lifestyle interventions; and understanding the pharmacogenomics of established, trial-tested, efficacious therapeutics to enable provision of more precise regimens will have no effect on improving the medication adherence problem that persists for many common drugs.

Unfortunately, many technological solutions designed to improve human health appear subject to what Toyama calls the Law of Amplification3, which asserts that technology is more apt to have positive impact when the underlying intentions and desires of the persons to whom the technology is being applied already exist in such a form so as to be amenable to amplification when a particular technology is introduced. So, over a century ago, when medical imaging advances first allowed internal bodily structures to be visualized without surgery, the technology quickly caught on (and remains widely prevalent today) as many medical professionals of the time already had an ingrained desire to view internal structures prior to the introduction of imaging [3] In contrast, resistance to EMRs might be partially related to physicians' lack of desire to increase time spent on documentation (despite EMRs other benefits). Ironically, though EMRs have been viewed as a partial solution to curbing health care costs, they may in some cases be having the unintended, opposite effect of encouraging more spending by amplifying intentions to over-order and overprescribe [4]. Though a somewhat techno-pessimist attitude has been taken in this commentary, even the most adamant anti-techno has to admit that, in many circumstances, technology undoubtedly is (will be) the preferred solution to a particular problem. But often it won't, despite techno-optimist's best efforts. This commentator simply asks problem-solvers to focus on solving the problem, not look for problems for which technology may provide a solution.

\section{References}

1. Topol EJ (2015) The Patient Will See You Now. Basic Books.

2. Sharda P (2016) Before Disrupting Healthcare: What Innovators Need to Know.

3. Jorgenson TJ (2016) Strange Glow. Princeton University Press.

4. Toyama K (2015) Geek Heresy. Public Affairs. 


\section{ISSN: 2574-1241}

DOI: 10.26717/BJSTR.2018.09.001858

Brent A Williams. Biomed J Sci \& Tech Res

(C) This work is licensed under Creative

Submission Link: https://biomedres.us/submit-manuscript.php

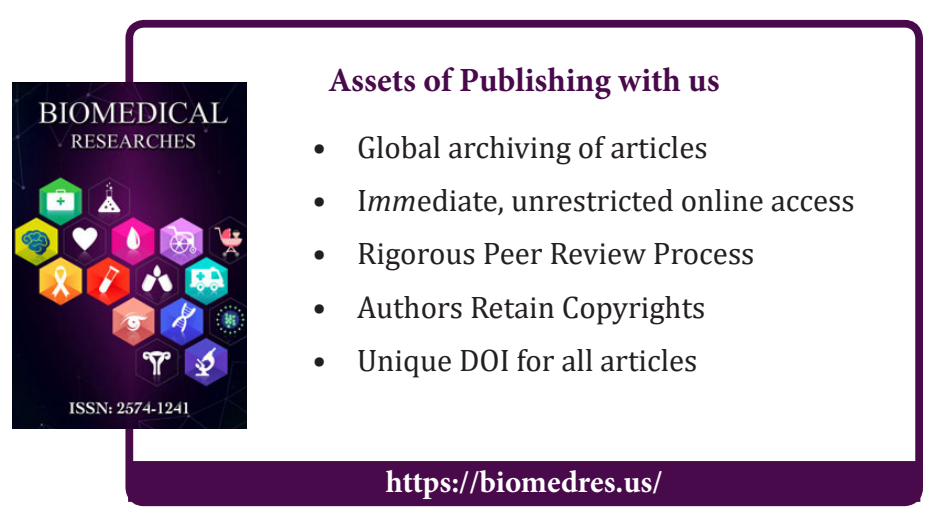

